\title{
BONY COCHLEAR NERVE CANAL IN CHILDREN WITH BILATERAL PROFOUND SENSORINEURAL HEARING LOSS - A PILOT STUDY
}

\author{
Dokoska Marija ${ }^{1}$, Davceva Chakar Marina ${ }^{1}$, Nikolova Sonja ${ }^{2}$, Kiteva-Trencevska \\ Gordana $^{3}$
}

\author{
${ }^{1}$ University Clinic for Ear, Nose and Throat, Faculty of Medicine, Ss. Cyril and Methodius \\ University in Skopje, R. North Macedonia \\ ${ }^{2}$ Institute of Radiology, Faculty of Medicine, Ss. Cyril and Methodius University in Skopje, \\ R. North Macedonia \\ ${ }^{3}$ University Clinic for Neurology, Faculty of Medicine, Ss. Cyril and Methodius University in \\ Skopje, R. North Macedonia \\ e-mail:m_dokoska@yahoo.com
}

\begin{abstract}
Introduction: The aim of this study was to evaluate the width of the bony cochlear nerve canal (BCNC) in children with congenital sensorineural hearing loss (SNHL) and "normal" findings on thin section temporal bone CT.

Material and methods: The width of the BCNC was retrospectively evaluated in two groups of patients. The study group included 11 children (22 bone canals) aged 2-12 years, with congenital, bilateral SNHL who underwent cochlear implantation (CI) from July to December 2019 and no abnormalities of the inner ear were detected on their preoperative CT scans. Eleven patients (22 bone canals), aged 3-10 years, in whom no sensorineural hearing loss had been diagnosed were taken as controls and CT scan of the temporal bone was performed for another reason - suspected acute mastoiditis, chronic otitis media, or perforation of the tympanic membrane. Axial sections of their CT scans were used to measure the width of the BCNC.

Results: BCNC width values in patients with bilateral, profound sensorineural hearing loss ranged from 1.0 to $2.3 \mathrm{~mm}$ and the mean value was $1.5 \pm 0.3 \mathrm{~mm}$. In patients with normal hearing, the values for the canal width were higher, with mean value of $2.1 \pm 0.3 \mathrm{~mm}$.

Conclusion: The results obtained showed that the width of the BCNC in children with bilateral, profound sensorineural hearing impairment was significantly smaller than in the control group with normal hearing for $\mathrm{p}<0.05$ (t-test=6.62912, $\mathrm{p}=0.000000$ ).

Keywords: bony cochlear nerve canal, children, congenital sensorineural hearing loss

\section{Introduction}

Sensorineural hearing loss is one of the most common defects present at birth, and affects 1-3 in every 1,000 newborns. The causes of hearing loss in children can be different. Deafness can be congenital or acquired, and it is estimated that even $20 \%$ of all cases of congenital sensorineural hearing loss are due to inner ear abnormalities involving the bony labyrinth [1]. With the introduction of universal neonatal hearing screening, deafness can be diagnosed in the first months of life and this allows early treatment and minimization of the
\end{abstract}


negative implications of this anomaly. For more than 30 years cochlear implantation (CI) has become a standard of care for children with profound sensorineural hearing loss. The cochlear implant is an innovative electronic device that converts the auditory signal into an electrical signal which in turn stimulates neurons in the spiral ganglion and thus transmits the signal through the cochlear nerve and central auditory pathway to the auditory cortex. Therefore, the integrity of the cochlear nerve is a major factor influencing the development of auditoryspeech performance after cochlear implantation.

Bony cochlear nerve canal, also referred to as the cochlear fossette, is a short bony canal between the base of the cochlear modulus and the fundus of the internal auditory canal and contains the cochlear nerve fibers that run from the spiral ganglion to the cochlear nerve. The width of the canal is directly correlated with the diameter of the cochlear nerve, so narrowed canal is associated with hypoplasia or aplasia of the cochlear nerve and sensorineural hearing loss $[2,3]$. According to the literature, patients with sensorineural hearing loss who are candidates for cochlear implantation and have a hypoplastic or absent cochlear nerve may have less benefit from the cochlear implant [4]. Papsin has shown that the benefits of cochlear implantation in patients with narrowed internal auditory canal (IAC) or cochlear nerve canal are smaller than in children who are implanted and do not have this abnormality [5]. Hence, preoperative assessment of its width is needed.

The aim of this study was to assess the width of the cochlear nerve canal in a series of children with bilateral, profound sensorineural hearing loss (b-SNHL) in whom no abnormalities of the high-resolution temporal bone computed tomography (TBCT) were detected comparable to the normal group of patients.

\section{Material and methods}

\section{Study Design and Patient Selection}

In this pilot study we retrospectively reviewed data from 11 children, with bilateral, congenital sensorineural hearing loss, who underwent CI in the period July-December 2019 at the University Clinic for Ear, Nose and Throat in Skopje. As part of the diagnostic protocol, in all children brainstem evoked response audiometry (BERA) was done and profound sensorineural hearing loss, which means absence of auditory responses at the strongest sound stimuli (in the range 80-100 dB) was confirmed. Also, all of them underwent preoperative CT scan of the temporal bone with a thin section and no abnormalities of the inner, middle and outer ear were detected.

To design a control group, we recruited 11 age-matched patients without sensorineural hearing loss. CT scan of the temporal bone in these children was performed for another reason such as suspecion of acute mastoiditis, chronic otitis media, or perforation of the tympanic membrane, and they also had a normal inner ear finding.

All 22 children underwent $0.5 \mathrm{~mm}$-thickness high-resolution TBCT on a 64-slice Somatom Definition AS + computed tomography (Siemens Healthiness, USA) at the Institute of Radiology, performed according to a standard temporal bone evaluation protocol. In addition, each cochlea was examined separately to check for possible malformation according to the Sennaroglu classification system [6].

\section{Radiodiagnostics and measurement of the width of the BCNC}

Axial plane images were used to measure the width of the BCNC. The diameter of the cochlear nerve canal was measured as a distance between the inner boundary of its bony walls in the middle of an axial section at the level of the base of the modulus. The BCNC is located between the bottom of the internal auditory canal (IAC) and the base of the cochlea 
and contains the nerve fibers that run from the spiral ganglion to the cochlear nerve [1] (Figure 1). Therefore, a narrow BCNC probably indicates an anatomical or functional defect of the cochlear nerve due to which the width of the cochlear nerve canal seems to be a reliable radiological marker of the presence and status of the cochlear nerve.

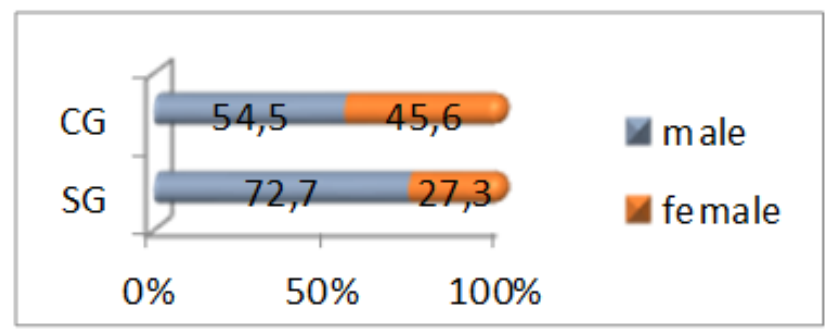

Fig. 1. Distribution by gender

Table 1. Distribution by gender

\begin{tabular}{lcccc}
\hline \multirow{2}{*}{ Gender } & \multicolumn{2}{c}{ SG } & \multicolumn{2}{c}{ CG } \\
& Number & \% & Number & \% \\
\hline Male & 8 & 72.7 & 6 & 54.5 \\
Female & 3 & 27.3 & 5 & 45.6 \\
Total & 11 & 100.0 & 11 & 100.0 \\
\hline
\end{tabular}

As these data represent appropriate pairs, the widths of a total of $22 \mathrm{BCNC}$ in the study group and $22 \mathrm{BCNC}$ in the control group were measured. From the obtained measurements, the following factors were considered retrospectively:

1) The range of the width of BCNC in the children with bilateral severe sensorineural hearing loss and the children in the control group.

2) The average value for the channel width in the groups was calculated and using the t-test their correlation was analyzed.

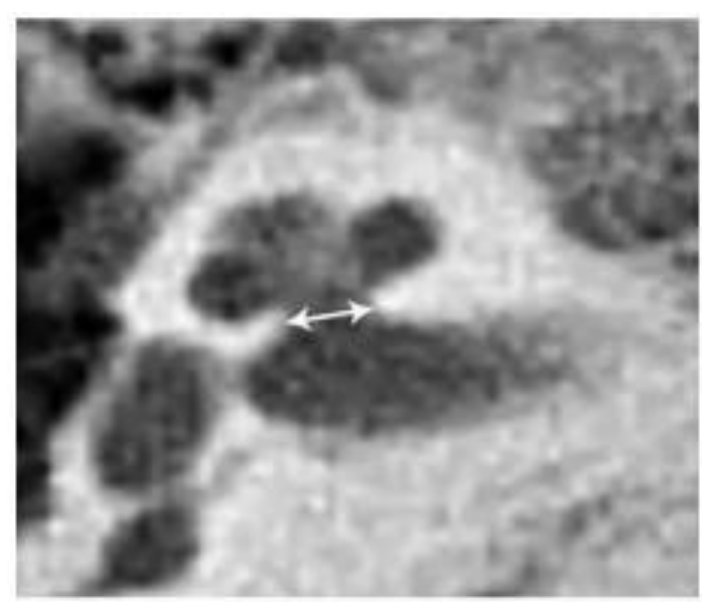

Fig. 2. Axial- length resolution CT section showing bony cochlear nerve canal diameter at the mid-modiolar level

\section{Results}

\section{Demographic Characteristics}

The study involved 22 children aged 2 to 12 years divided into two groups, the study group (SG) consisting of 11 children with congenital, bilateral SNHL and 11 children without 
hearing impairment (control group - CG). $72.7 \%$ of children with SNHL were boys and 27.3\% were girls; the percentage difference registered in relation to gender was statistically significant for $\mathrm{p}<0.05$ (Difference test, $\mathrm{p}=0.0332$ ). In CG 54.5\% were boys, and $45.6 \%$ were girls; the percentage difference was statistically insignificant for $\mathrm{p}>0.05$ (Table and Figure 1). The mean age of the children in the study group was $4.8 \pm 3.7$ years, minimum 2 years; maximum $12.50 \%$ of patients were older than 3 years for median IQR=3 (2-8) (Table 2). The mean age of patients in the control group was $6.27 \pm 2.63$ (Table 3) and there was no significant age difference between the two groups.

Table 2. Display of the mean age of children in the study group

\begin{tabular}{cccccccc}
\hline $\begin{array}{c}\text { Number } \\
(\mathbf{N})\end{array}$ & $\begin{array}{c}\text { Average } \\
\text { (Mean) }\end{array}$ & $\begin{array}{c}\text { Standard } \\
\text { deviation } \\
\text { (Std. Dev.) }\end{array}$ & $\begin{array}{c}\text { Minimum } \\
\text { (Min) }\end{array}$ & $\begin{array}{c}\text { Maximum } \\
\text { (Max) }\end{array}$ & 25th & $\begin{array}{c}\text { Percentiles } \\
\text { 50th } \\
\text { (Median) }\end{array}$ & 75th \\
\hline 11 & 4.8 & 3.7 & 2.0 & 12.0 & 2.0 & 3.0 & 8.0 \\
\hline
\end{tabular}

Table 3. Display of the mean age of children in the control group

\begin{tabular}{cccccccc}
\hline $\begin{array}{c}\text { Number } \\
(\mathbf{N})\end{array}$ & $\begin{array}{c}\text { Average } \\
\text { (Mean) }\end{array}$ & $\begin{array}{c}\text { Standard } \\
\text { deviation } \\
\text { (Std. Dev.) }\end{array}$ & $\begin{array}{c}\text { Minimum } \\
\text { (Min) }\end{array}$ & $\begin{array}{c}\text { Maximum } \\
\text { (Max) }\end{array}$ & 25th & $\begin{array}{c}\text { Percentiles } \\
\text { 50th } \\
\text { (Median) }\end{array}$ & 75th \\
\hline 11 & 6.27 & 2.63 & 3.0 & 10.0 & 4.0 & 6.0 & 9.0 \\
\hline
\end{tabular}

\section{Radiologic Parameters of the BCNC and Cut-off Values for the Width}

The analyzed data represented batch pairs (two measurements were obtained from one patient - left and right BCNC), and hence, separate and summarized calculations of the mean value of the width were made. The average value of the canal in the right ear in SG was $1.5 \pm 0.3 \mathrm{~mm}$, minimum $1.0 \mathrm{~mm}$, maximum $2.1 \mathrm{~mm}$; in $50 \%$ of patients the width was more than $1.5 \mathrm{~mm}$ for median $\mathrm{IQR}=1.5(1.3-1.7)$. The average value of the canal in the right ear in CG was $2.1 \pm 0.2 \mathrm{~mm}$, minimum $1.7 \mathrm{~mm}$, maximum $2.4 \mathrm{~mm}$; in $50 \%$ of patients the width was more than $2.0 \mathrm{~mm}$ for median IQR=2.0 (1.8-2.3) (Table 4 and Figure 2).

According to the t-test, the difference between the average values of the right ear canal width of SG and CG was statistically significant for $\mathrm{p}<0.05$ (t-test $=4.52776$, $\mathrm{p}=0.000205$ ).

Table 4. Average width of the right BCNC in both groups

\begin{tabular}{ccccccccc}
\hline $\begin{array}{c}\text { Right } \\
\text { ear }\end{array}$ & $\begin{array}{c}\text { Number } \\
\text { (N) }\end{array}$ & $\begin{array}{c}\text { Average } \\
\text { (Mean) }\end{array}$ & $\begin{array}{c}\text { Standard } \\
\text { deviation } \\
\text { (Std. Dev.) }\end{array}$ & $\begin{array}{c}\text { Minimum } \\
\text { (Min) }\end{array}$ & $\begin{array}{c}\text { Maximum } \\
\text { (Max) }\end{array}$ & 25th & $\begin{array}{c}\text { Percentiles } \\
\text { 50th } \\
\text { (Median) }\end{array}$ & 75th \\
\hline SG & 11 & 1.5 & 0.3 & 1.0 & 2.1 & 1.3 & 1.5 & 1.7 \\
CG & 11 & 2.1 & 0.2 & 1.7 & 2.4 & 1.8 & 2.0 & 2.3 \\
\hline
\end{tabular}

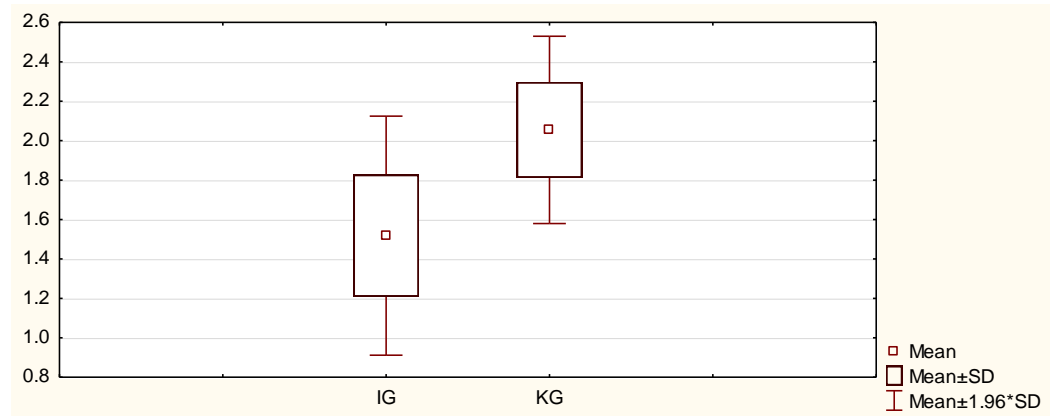

Fig. 2. Average width of the right $\mathrm{BCNC}$ in both groups 
Table 5. Average width of the left BCNC in both groups

\begin{tabular}{ccccccccc}
\hline $\begin{array}{c}\text { Right } \\
\text { ear }\end{array}$ & $\begin{array}{c}\text { Number } \\
\text { (N) }\end{array}$ & $\begin{array}{c}\text { Average } \\
\text { (Mean) }\end{array}$ & $\begin{array}{c}\text { Standard } \\
\text { deviation } \\
\text { (Std. Dev.) }\end{array}$ & $\begin{array}{c}\text { Minimum } \\
\text { (Min) }\end{array}$ & $\begin{array}{c}\text { Maximum } \\
\text { (Max) }\end{array}$ & 25th & $\begin{array}{c}\text { Percentiles } \\
\text { 50th } \\
\text { (Median) }\end{array}$ & 75th \\
\hline SG & 11 & 1.5 & 0.4 & 1.1 & 2.3 & 1.3 & 1.5 & 1.8 \\
CG & 11 & 2.1 & 0.2 & 1.8 & 2.5 & 2.0 & 2.1 & 2.2 \\
\hline
\end{tabular}

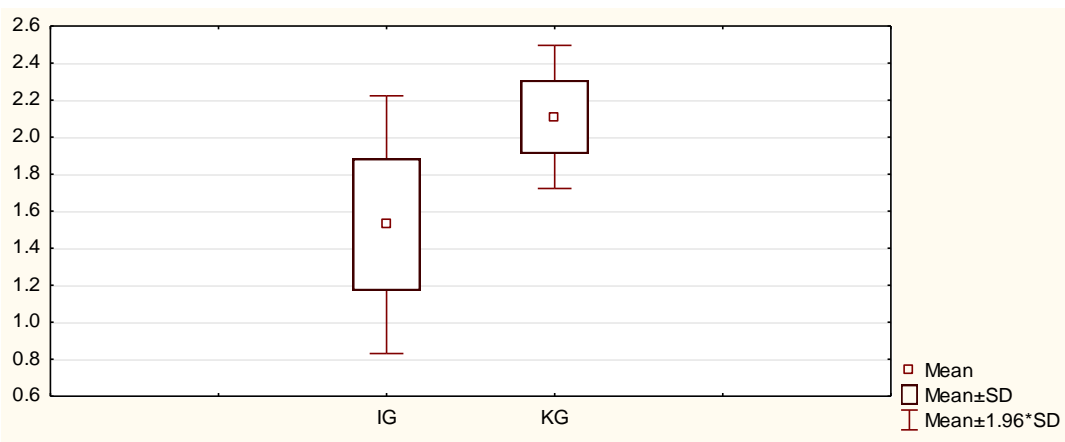

Fig. 3. Average width of the left $\mathrm{BCNC}$ in both groups

The average value of the canal in the left ear in SG was $1.5 \pm 0.4 \mathrm{~mm}$, minimum 1.1 $\mathrm{mm}$, maximum $2.3 \mathrm{~mm}$; in $50 \%$ of patients the width was more than $1.5 \mathrm{~mm}$ for median IQR $=1.5$ (1.3-1.8). The average value of the canal in the left ear in CG was $2.1 \pm 0.2 \mathrm{~mm}$, minimum $1.8 \mathrm{~mm}$, maximum $2.5 \mathrm{~mm}$; in $50 \%$ of patients the width was more than $2.1 \mathrm{~mm}$ for median $\mathrm{IQR}=2.1(2.0-2.2)$ (Table 5 and Figure 3).

According to the t-test, the difference between the average values of the left ear canal width of SG and CG was statistically significant for $\mathrm{p}<0.05$ (t-test=4.74922, $\mathrm{p}=0.000123$ ).

The difference between the average values expressed in $\mathrm{mm}$ between left and right ear in $S G$ was statistically insignificant for $\mathrm{p}>0.05$ ( $\mathrm{t}$-test $=0.0640018, \mathrm{p}=0.949591$ ).

The difference between the average values expressed in mm between left and right ear in CG was statistically insignificant for $\mathrm{p}>0.05$ ( $\mathrm{t}$-test $=0.578961, \mathrm{p}=0.569080$ ).

The average value of the BCNC width in SG was $1.5 \pm 0.3 \mathrm{~mm}$, minimum $1.0 \mathrm{~mm}$, maximum $2.3 \mathrm{~mm}$; in 50\% of patients the width was below $1.5 \mathrm{~mm}$ for Median IQR=1.5 (1.3-1.7).

The average value of the BCNC width in CG was $2.1 \pm 0.3 \mathrm{~mm}$, minimum $1.0 \mathrm{~mm}$, maximum $2.5 \mathrm{~mm}$; in $50 \%$ of patients the width was more than $2.15 \mathrm{~mm}$ for median IQR= 2.15 (1.9-2.3) (Table 6 and Figure 4).

According to the t-test, the difference in the mean values for the width of the BCNC between SG and CG was statistically significant for $\mathrm{p}<0.05$ ( $\mathrm{t}$-test=6.62912, $\mathrm{p}=0.000000$ ).

Table 6. Average width of the BCNC in both groups

\begin{tabular}{lcccccccc}
\hline & $\begin{array}{c}\text { Number } \\
(\mathbf{N})\end{array}$ & $\begin{array}{c}\text { Average } \\
(\text { Mean) }\end{array}$ & $\begin{array}{c}\text { Standard } \\
\text { deviation } \\
\text { (Std. Dev.) }\end{array}$ & $\begin{array}{c}\text { Minimum } \\
\text { (Min) }\end{array}$ & $\begin{array}{c}\text { Maximum } \\
\text { (Max) }\end{array}$ & 25th & $\begin{array}{c}\text { Percentiles } \\
\text { 50th }\end{array}$ & 75th \\
\hline SG & 22 & 1.5 & 0.3 & 1.0 & 2.3 & 1.3 & 1.5 & 1.7 \\
CG & 22 & 2.1 & 0.3 & 1.7 & 2.5 & 1.9 & 2.15 & 2.3 \\
\hline
\end{tabular}




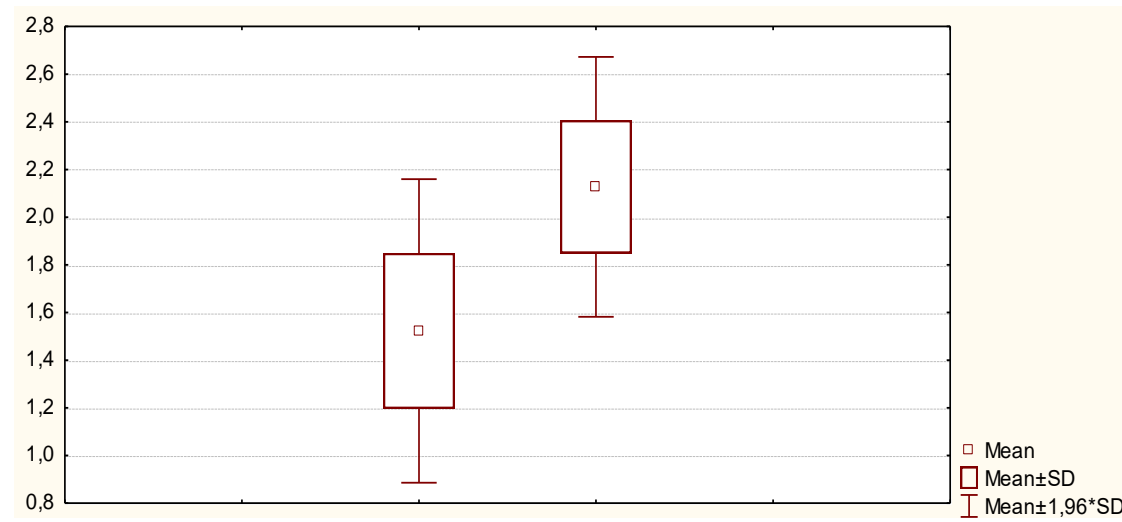

Fig. 4. Average width of the BCNC in both groups with B-SNHL Normal hearing group

Table 7. Temporal bones in patients with normal hearing

\begin{tabular}{|c|c|c|c|c|}
\hline Study & $\begin{array}{l}\text { Temporal bones } \\
\text { Studied }(\mathbf{N})\end{array}$ & Technique & Slice & $\begin{array}{c}\text { CNC, Width, } \\
\text { Mean (SD), mm }\end{array}$ \\
\hline Fatterpekar et al., $1999^{2}$ & 100 & $\mathrm{CT}$ & $1 \mathrm{~mm}$ & $2.13(0.44)$ \\
\hline Stjernholm and Muren, $2002^{9}$ & 100 & $\mathrm{CT}$ & $1 \mathrm{~mm}$ & $1.91(0.24)$ \\
\hline Hender et al., $2011^{10}$ & 110 & \multicolumn{2}{|c|}{$\begin{array}{l}\text { Harvested } 2-\mu \mathrm{m} \text { slide } \\
\text { temporal bones }\end{array}$} & $2.26(0.25)$ \\
\hline Current study & 22 & $\mathrm{CT}$ & $0.5 \mathrm{~mm}$ & $2.1(0.3)$ \\
\hline
\end{tabular}

Table 8. Temporal bones in patients with SNHL

\begin{tabular}{lcccc}
\multicolumn{1}{c}{ Study } & $\begin{array}{c}\text { Temporal bones } \\
\text { Studied (N) }\end{array}$ & Technique & Slice & $\begin{array}{c}\text { CNC, Width, } \\
\text { Mean (SD), mm }\end{array}$ \\
\hline Fatterpekar et al., 2000 & 100 & CT & $1 \mathrm{~mm}$ & $1.82(0.24)$ \\
Abigail et al., $2012^{8}$ & 85 & CT & $1 \mathrm{~mm}$ & $0.98(0.57)$ \\
Current study & 22 & CT & $0.5 \mathrm{~mm}$ & $1.5(0.3)$ \\
\hline
\end{tabular}

\section{Discussion}

The data from the literature show that there is no consensus regarding the question of what is normal width and what is stenosis or hypoplasia of the bony canal of the cochlear nerve. According to various authors, several numerical criteria have been proposed for the determination of canal stenosis, BCNC (less than 1.2-1.82) [7, 8]. Fatterpekar was the first who measured the width of the BCNC using CT. According to him, the average value of the canal width in patients without sensorineural hearing loss was $2.13 \pm 0.44$ and it was significantly higher than that in patients with severe, bilateral sensorineural hearing loss (1.82 \pm 0.24$)$ [2]. Stjernholm and Muren measured 117 temporal bone silicone molds, and 16 of them compared the dimensions measured in this way with the dimensions measured on the corresponding CT images of these samples. According to the results of their measurements, BCNC with a width $<1.4 \mathrm{~mm}$ was considered to be a very narrow channel and $\mathrm{BCNC}>3 \mathrm{~mm}$ was considered to be an abnormally wide channel [9].

The results obtained in our study showed that the average value of the BCNC channel width in SG was $1.5 \pm 0.3 \mathrm{~mm}$, minimum $1.0 \mathrm{~mm}$, maximum $2.3 \mathrm{~mm}$; in $50 \%$ of patients the width was below $1.5 \mathrm{~mm}$ for median $\mathrm{IQR}=1.5(1.3-1.7)$, and the average value of the channel width in CG was $2.1 \pm 0.3 \mathrm{~mm}$, minimum $1.0 \mathrm{~mm}$, maximum $2.9 \mathrm{~mm}$; in $50 \%$ of patients the width was more than $2.15 \mathrm{~mm}$ for median IQR=2.15 (1.9-BCNC 2.3) (Table 6).

According to the t-test, the mean value for BCNC width in patients with severe, bilateral sensorineural hearing loss compared to patients with normal hearing was statistically significantly lower $(\mathrm{p}<0.05)(\mathrm{t}$-test $=6.62912, \mathrm{p}=0.000000)$. 
However, the authors of this study and the literature agree on two findings: 1. Patients with sensorineural hearing loss are much more likely to have a smaller canal than those with normal hearing, and 2. Narrow BCNC detected on CT is a serious indicator of possible presence of hypoplasia or aplasia of the cochlear nerve.

The reason why this channel is narrower in patients with sensorineural hearing loss is not yet clear but it is assumed that the answer lies in the embryonic development. Namely, during development, the internal auditory canal (IAC) is transformed from a mesodermal layer into cartilage tissue and eventually into a bone canal. During the same period, the cochlear nerve channel (CNC) is formed, which requires stimulation for normal development. Because the IAC is formed around the vestibular-cochlear nerve (VCN) neuronal fibers, stenosis of the IAC and CNC is probably due to the lack of sufficient stimulus for normal development due to hypoplasia or cochlear nerve aplasia [11].

Patients with a cochlear implant who have a cochlear nerve deficiency (hypoplasia or aplasia) show significantly worse postoperative results, so these findings are particularly important for physicians evaluating children with sensorineural hearing loss who are candidates for cochlear implant.

Radiodiagnostics plays a very important role in the preoperative evaluation of patients who are candidates for cochlear implantation. It enables preoperative detection of congenital or acquired abnormalities of the inner ear and cochlear nerve, and also provides the surgeon with information on other possible variations in temporal bone anatomy that are important for the surgical approach or indicate possible difficulties during the intervention. The optimal protocol for radiodiagnostics has not yet been defined. CT and MRI are complementary methods and both are being used for this purpose. MRI is a gold standard for CN detection. CT is a historical and current method of choice in the diagnostic treatment of patients before implanttation in a number of institutions around the world that deal with cochlear implantation. However, because this method does not directly show the cochlear nerve, the narrowed BCNC on CT may be an indicator for the selection of children with sensorineural hearing loss who will need to be referred to an MRI for direct visualization of the cochlear nerve. and a definitive assessment of the presence of hypoplasia or cochlear nerve aplasia which is the only absolute contraindication to cochlear implant placement.

\section{Conclusion}

In this pilot study, the mean value of BCNC width in patients with severe bilateral sensorineural hearing loss was $1.5 \pm 0.3 \mathrm{~mm}$ and was statistically significantly lower by $\mathrm{p}$ $<0.05$ (t-test=6.62912, $\mathrm{p}=0.000000)$ calculated with an average $\mathrm{BCNC}$ width value $(2.1 \pm 0.3)$ $\mathrm{mm}$ in patients with normal hearing. The average value of $1.5 \mathrm{~mm}$ will be taken as the limit width and all values below this will be defined as a stenotic or stent channel.

The results of this study will be used to further investigate whether the outcome of cochlear implantation in deaf children is directly correlated to BCNC width. These data are of great importance in the preoperative assessment of prelingually deaf children and in reaching a decision whether they are suitable for a cochlear implant or some other type of implant. This is of substantial importance for the children's hearing and language development and their timely socialization.

Conflict of interest statement. None declared. 


\section{References}

1. Tahir E, Bajin MD, Atay G, Mocan BÖ, Sennaroğlu L. Bony cochlear nerve canal and internal auditory canal measures predict cochlear nerve status. J Laryngol Otol 2017; 131(8): 676-83.

2. Fatterpekar GM, Mukherji SK, Alley J, Lin Y, Castillo M. Hypoplasia of the bony canal for the cochlear nerve in patients with congenital sensorineural hearing loss: initial observations. Radiology 2000; 215(1): 243-6.

3. Miyasaka M, Nosaka S, Morimoto N, Taiji H, Masaki H. CT and MR imaging for pediatric cochlear implantation: emphasis on the relationship between the cochlear nerve canal and the cochlear nerve. Pediatr Radiol 2010; 40: 1509-16.

4. Kang BC, Lee JY, Kim Y, Park JW, Kang WS, Ahn JH, et al. Outcome of Cochlear Implantation in Children with Narrow Bony Cochlear Nerve Canal. Otol Neurotol 2019; 40(7): e679-e685.

5. Papsin BC. Cochlear implantation in children with anomalous cochleovestibular anatomy. Laryngoscope 2005; 115(1 Pt 2 Suppl 106): 1-26.

6. Sennaroglu L. Cochlear implantation in inner ear malformations: a review article. Cochlear Implant Int 2010; 11: 4-41.

7. Kim H, Kim DY, Ha EJ, Park HY. Clinical Value of Measurement of Internal Auditory Canal in Pediatric Cochlear Implantation. Ann Otol Rhinol Laryngol 2019; 128(6_suppl): 61S-68S.

8. Wilkins A, Prabhu SP, Huang L, Ogando PB, Kenna MA. Frequent association of cochlear nerve canal stenosis with pediatric sensorineural hearing loss. Arch Otolaryngol Head Neck Surg 2012; 138(4): 383-8.

9. Stjernholm C, Muren C. Dimensions of the cochlear nerve canal: a radioanatomic investigation. Acta Otolaryngol 2002; 122(1): 43-8.

10. Henderson E, Wilkins A, Huang L, Kenna M, Gopen Q. Histopathological investigation of the cochlear nerve canal in normal temporal bones. Int J Pediatr Otorhinolaryngol 2011; 75(4): 464-7.

11. Mcphee JR, Van De Water Tr. Epithelial-mesenchymal tissue interactions guiding otic capsule formation: the role of the otocyst. J Embryol Exp Morphol 1986; 97: 1-24. 